\title{
Acute sleep fragmentation does not alter pro-inflammatory cytokine gene expression in brain or peripheral tissues of leptin-deficient mice
}

\author{
Jennifer E Dumaine ${ }^{1}{ }$, Noah T Ashley ${ }^{\text {Corresp. } 2}$ \\ ${ }^{1}$ School of Veterinary Medicine, University of Pennsylvania, Philadelphia, PA, United States \\ 2 Department of Biology, Western Kentucky University, Bowling Green, Kentucky, United States \\ Corresponding Author: Noah T Ashley \\ Email address: noah.ashley@wku.edu
}

Obesity and sleep fragmentation (SF) are often co-occurring pro-inflammatory conditions in patients with obstructive sleep apnea (OSA). Leptin is a peptide hormone produced by adipocytes that has anorexigenic effects upon appetite while regulating immunity. The role of leptin in mediating inflammatory responses to SF is incompletely understood. Male C57BL/6j (lean) and ob/ob mice (leptin-deficient mice exhibiting obese phenotype) were subjected to SF or control conditions for 24 hours using an automated SF chamber. Trunk blood and tissue samples from the periphery (liver, spleen, fat, and heart) and brain (hypothalamus, prefrontal cortex, and hippocampus) were collected. Quantitative PCR was used to determine relative cytokine gene expression of pro-inflammatory (IL-1 $\beta$, TNF- $\alpha$ ) and anti-inflammatory (TGF- $\beta 1$ ) cytokines. ELISA was used to determine serum corticosterone concentration. Ob/ob mice exhibited elevated cytokine gene expression in liver (TNF- $\alpha$, TGF- $\beta 1$ ), heart (TGF- $\beta 1$ ), fat (TNF- $\alpha$ ) and brain (hippocampus, hypothalamus, prefrontal cortex: IL-1 $\beta$, TNF- $\alpha$ ) compared with wild-type mice. Conversely, leptin deficiency decreased pro-inflammatory cytokine gene expression in heart (IL-1 $\beta$, TNF- $\alpha$ ). SF significantly increased IL-1 $\beta$ and TNF- $\alpha$ gene expression in fat and TGF- $\beta 1$ expression in spleen relative to controls, but only in wild-type mice. SF increased basal serum corticosterone regardless of genotype. Taken together, these findings suggest that leptin deficiency affects cytokine gene expression differently in the brain compared to peripheral tissues with minimal interaction from acute sleep fragmentation. 
1 Acute sleep fragmentation does not alter pro-inflammatory cytokine gene expression in brain or 2 peripheral tissues of leptin-deficient mice

3 Jennifer E. Dumaine ${ }^{1 \uparrow}$, Noah T. Ashley ${ }^{1 *}$

41 Dept. of Biology, Western Kentucky University, Bowling Green, KY USA

$5 *$ Author for correspondence.

6 For submission to: PeerJ

$7{ }^{*}$ Dept. of Biology Western Kentucky University, 1906 College Heights Blvd. Bowling Green, $8 \mathrm{KY}$

9

10 USA 1-(270) 745-4268; (270) 745-6856 (fax), noah.ashley@wku.edu

11 The authors declare no conflict of interest.

12 Current address: School of Veterinary Medicine; University of Pennsylvania, Philadelphia, PA 


\section{Abstract}

15 Obesity and sleep fragmentation (SF) are often co-occurring pro-inflammatory conditions in

16 patients with obstructive sleep apnea (OSA). Leptin is a peptide hormone produced by

17 adipocytes that has anorexigenic effects upon appetite while regulating immunity. The role of

18 leptin in mediating inflammatory responses to SF is incompletely understood. Male C57BL/6j

19 (lean) and ob/ob mice (leptin-deficient mice exhibiting obese phenotype) were subjected to SF or

20 control conditions for 24 hours using an automated SF chamber. Trunk blood and tissue samples

21 from the periphery (liver, spleen, fat, and heart) and brain (hypothalamus, prefrontal cortex, and

22 hippocampus) were collected. Quantitative PCR was used to determine relative cytokine gene

23 expression of pro-inflammatory (IL-1 $\beta, \mathrm{TNF}-\alpha$ ) and anti-inflammatory (TGF- $\beta 1$ ) cytokines.

24 ELISA was used to determine serum corticosterone concentration. Ob/ob mice exhibited

25 elevated cytokine gene expression in liver (TNF- $\alpha$, TGF- $\beta 1$ ), heart (TGF- $\beta 1$ ), fat (TNF- $\alpha$ ) and

26 brain (hippocampus, hypothalamus, prefrontal cortex: IL-1 $\beta$, TNF- $\alpha$ ) compared with wild-type

27 mice. Conversely, leptin deficiency decreased pro-inflammatory cytokine gene expression in

28 heart (IL-1 $\beta$, TNF- $\alpha$ ). SF significantly increased IL- $1 \beta$ and TNF- $\alpha$ gene expression in fat and

29 TGF- $\beta 1$ expression in spleen relative to controls, but only in wild-type mice. SF increased basal

30 serum corticosterone regardless of genotype. Taken together, these findings suggest that leptin

31 deficiency affects cytokine gene expression differently in the brain compared to peripheral

32 tissues with minimal interaction from acute sleep fragmentation. 
36

37

38

39

40

41

42

43

44

45

46

47

48

49

50

51

52

53

54

55

56

57

\section{Introduction}

In conjunction with the worldwide obesity epidemic, the number of individuals suffering from sleep disorders continues to rise (Peppard et al. 2013). Obesity is a chronic low-grade proinflammatory condition, with adipose tissue exhibiting both paracrine and endocrine functions. Leptin is an adipokine that regulates metabolic functions, such as insulin sensitivity and glucose tolerance (Fu et al. 2015; O'Donnell et al. 2000). Leptin is secreted by adipose tissue, where it then circulates to the hypothalamus to act as a satiety hormone. Serum leptin levels are directly related to adipose tissue mass, which leads to increased leptin levels associated with the obese phenotype (Al Maskari \& Alnaqdy 2006). Although obesity increases serum leptin concentration, there is no corresponding loss of appetite, which suggests resistance of individuals to the actions of this hormone (O'Donnell et al. 2000). In addition to having metabolic functions, leptin regulates the sleep-wake cycle, as leptin-deficient mice exhibit more frequent, shorterduration sleep periods, increased bouts of REM sleep, and decreased recovery to sleep deprivation (Laposky et al. 2006). Although leptin can act as a pro-inflammatory signal (Besedovsky et al. 2012), mice that are deficient in leptin (ob/ob) or possess a defective leptin receptor $(\mathrm{db} / \mathrm{db}$ and $\mathrm{fa} / \mathrm{fa})$ are morbidly obese and display elevated pro-inflammatory cytokines in peripheral tissues and brain (Dube et al. 2008; Fruhbeck et al. 2017; Mirsoian et al. 2014; Sainz et al. 2010). This suggests that excessive adiposity overrides the absence of leptin to promote a low-grade inflammatory environment in these tissues.

Due to alterations in leptin concentrations following sleep fragmentation in obstructive sleep apnea (OSA), it has been hypothesized that leptin can be used as a biomarker to detect the presence of sleep disorders (Ozturk et al. 2003; Pan \& Kastin 2014). Despite this proposed relationship, previous attempts have yet to successfully correlate leptin and leptin gene receptor 
59 polymorphisms with OSA (Lv et al. 2015). Additional experiments in rats, mice, and humans

60 have reported conflicting results as to whether leptin concentrations increase or decrease

61 following sleep fragmentation (Fu et al. 2015; Garcia-Garcia et al. 2014; Ozturk et al. 2003). In

62 lieu of this variation, it can be concluded that leptin concentrations are affected by both sleep

63 fragmentation (SF) and obesity, but their interaction is incompletely understood.

64

65

66

While pathologies associated with OSA are due to chronic exposure, an acute model of sleep fragmentation from our laboratory shows that acute SF rapidly induces characteristic changes in pro-inflammatory cytokine gene expression in the periphery and brain (Dumaine \& Ashley 2015). Interleukin-1-beta (IL-1 $\beta$ ) and tumor necrosis factor-alpha (TNF- $\alpha$ ) are two major pro-inflammatory cytokines that induce a wide variety of inflammatory events (Dinarello 2010) whereas TGF- $\beta 1$ is generally considered an anti-inflammatory cytokine that suppresses production of pro-inflammatory cytokines and innate immune cells (Sanjabi et al. 2009). Among C57BL/6j mice, $24 \mathrm{~h}$ of SF leads to an upregulation of IL-1 $\beta$ expression in adipose tissue, heart, and hypothalamus, as well as increased expression of TGF- $\beta 1$ in the hippocampus and prefrontal cortex (Dumaine \& Ashley 2015). Although the simultaneous effects of obesity and SF have been studied within the context of neurobehavior, the effects upon peripheral and neuroinflammatory responses remain poorly understood (He et al. 2015). The ob/ob KO mouse strain was chosen for this experiment to assess the simultaneous effects of SF and the absence of leptin responsiveness, as is the case with a portion of the obstructive sleep apnea (OSA) disease population. We predicted that sleep fragmentation would exacerbate peripheral and brain inflammation in leptin-deficient mice compared with wild-type controls, suggesting an additive effect of SF and leptin deficiency. 
81

82 Materials and Methods

83 Animals

84 Male C57BL/6j mice $(n=16)$ and ob/ob leptin gene knockout $(\mathrm{KO})$ mice (background,

$85 \mathrm{C} 57 \mathrm{BL} / 6 \mathrm{~J} ; n=18)$ were housed in a colony room $\left(12 \mathrm{~h} \mathrm{light} / 12 \mathrm{~h}\right.$ dark, lights on $07: 00 \mathrm{~h} ; 21^{\circ} \mathrm{C}$

$86 \pm 1^{\circ} \mathrm{C}$ ) at Western Kentucky University. To obtain the ob/ob KO mice, Jackson Laboratory ob

87 heterozygotes were purchased and bred. After weaning at $21 \mathrm{~d}$ of age, pups resided in

88 polypropylene cages with same sex littermates and were provided corncob bedding and food

89 (Rodent RM4 1800 diet (18\% protein, 5\% fat, 4\% fiber), Cincinnati Lab Supply) and water ad

90 libitum. Offspring lacking the leptin gene (ob/ob KO) were identified phenotypically by

91 screening individuals for weight gain $c a .4$ weeks of age. This study was conducted under

92 approval of the Institutional Animal Care Committee at Western Kentucky University (\#15-11)

93 and procedures followed the National Institutes of Health Guide for the Use and Care of

94 Laboratory Animals and international ethical standards.

\section{Sleep fragmentation}

96 Male adult ( $>8$ weeks of age) ob/ob mice and wild-type mice were briefly exposed to isoflurane

97 vapors and weighed to the nearest $0.01 \mathrm{~g}$, and then placed in an automated sleep fragmentation

98 chamber (Model 80391; Lafayette Instrument Company; Lafayette, IN USA) with a thin layer of

99 corn cob bedding at 09:00 h. Food and water were provided ad libitum. To distinguish among

100 subjects, tails were marked with a different colored pen (Sharpie). Following a $23 \mathrm{~h}$ habituation

101 period, the swipe bar was activated at 08:00 the next day. For this group, the swipe bar interval 
102 was set to 20 seconds based upon the results of previous experiments using telemetric

103 transmitters to measure EEG and EMG for validation of sleep fragmentation by this method

104 (Ramesh et al. 2009). Thus, each mouse receives 1,400 bar sweeps over $24 \mathrm{~h}$. This value

105 exceeds by an order of magnitude the number of baseline arousals that typically occur in ob/ob

106 and wild-type mice, respectively, in similar conditions (see Table 2; Laposky et al. 2006). For

107 the control group, the bar remained stationary. Thirty-four mice were pseudo-randomly assigned

108 to either control $(n=8), \mathrm{SF}(n=8)$, obese (OB) control $(n=9)$, or obese (OB) SF groups $(n=9)$.

109 One mouse in the OB SF group was removed during the experiment due to health reasons.

110 Sample sizes were determined based upon previous experiments (Dumaine \& Ashley 2015).

111 After $24 \mathrm{~h}$, animals were anesthetized using isoflurane vapors $(<2 \mathrm{~min})$, weighed, and

112 rapidly decapitated within 3 min of initial handling. Trunk blood was collected, kept on ice for $<$

$11320 \mathrm{~min}$, and spun at $3000 \mathrm{x}$ g for 30 minutes at $4^{\circ} \mathrm{C}$. Serum was drawn off and stored at $-80^{\circ} \mathrm{C}$

114 for ELISA analysis. Liver, spleen, epididymal fat (EWAT), and heart samples were collected

115 and placed into Eppendorf tubes containing RNAlater solution (Life Technologies). The tissue

116 samples were stored at $4^{\circ} \mathrm{C}$ until RNA extraction. The hippocampus, hypothalamus, and

117 prefrontal cortex were dissected from the brain and stored in RNAlater at $-20^{\circ} \mathrm{C}$ until RNA

118 extraction. 


\section{RNA Extraction}

121 RNA was extracted from brain, liver, spleen, and fat using an RNeasy Mini Kit (Qiagen). RNA

122 was extracted from the heart using an RNeasy Fibrous Tissue Mini Kit. RNA concentration was

123 measured using a NanoDrop 2000 Spectrophotometer (Thermo Scientific).

\section{Reverse Transcription}

126 Total RNA was reverse transcribed into cDNA using a High-Capacity cDNA Reverse

127 Transcription kit (Life Technologies, \#4368813). The reaction was carried out according to the

128 manufacturer's instructions. Amplification conditions for the thermocycler were $25^{\circ} \mathrm{C}$ for 10

$129 \min , 37^{\circ} \mathrm{C}$ for $120 \mathrm{~min}, 85^{\circ} \mathrm{C}$ for $5 \min \left(\right.$ for 1 cycle), then $4^{\circ} \mathrm{C}$.

\section{RT-PCR}

131 Real Time- PCR was performed using an ABI 7300 RT-PCR System. To determine relative

132 cytokine gene expression, Taqman Gene Expression RT-PCR Master Mix and the following

133 primer/probes (Applied Biosystems) were used: IL-1 $\beta$ (Mm00434228_m1), TNF- $\alpha$

134 (Mm00443260_g1), and TGF-ß1 (Mm01178820_m1), or 18s endogenous primer-limited

135 (Mm03928990_g1). Cytokine probes were labeled with the fluorescent marker 5-FAM at the 5'

136 end and the quencher MGB at the 3' end. The 18s endogenous control used a VIC-labeled probe.

137 Amplification conditions were $50^{\circ} \mathrm{C}$ for $2 \mathrm{~min}, 95^{\circ} \mathrm{C}$ for $10 \mathrm{~min}, 40$ cycles of $95^{\circ} \mathrm{C}$ for 15

138 seconds, and $60^{\circ} \mathrm{C}$ for $1 \mathrm{~min}$. The reaction was carried out in duplicate according to the 
139 manufacturer's instructions, and the relative expression of IL- $1 \beta$, TNF- $\alpha$, and TGF- $\beta 1$ was

140 determined by comparison with the standard curve generated using serial dilutions of pooled

141 cDNA $(1: 1,1: 10,1: 100,1: 1000,1: 10000)$ and normalization to the control 18s ribosomal RNA

142 levels and calibrator samples.

143

144 ELISA

145 Serum corticosterone concentration was determined using an ELISA kit (ab108821; Abcam)

146 with $96 \%$ recovery for corticosterone $(0.3 \mathrm{ng} / \mathrm{mL}$ sensitivity $)$. The reagents and standards were

147 prepared according to the manufacturer's instructions. Cross reactivities for the kit were $<30 \%$

148 deoxycorticosterone, $<2 \%$ aldosterone, $<2 \%$ progesterone, and $<1 \%$ cortexolone. Serum

149 samples were diluted 1:200 and plated in duplicate. The intraassay variation was 5.0\% CV.

150

151 Statistical Analyses

152 All data were expressed as mean \pm standard error (SE). Two-way ANOVAs were used to detect

153 differences among groups, with sleep treatment (control (no SF) vs. SF), genotype (wildtype vs.

$154 \mathrm{ob} / \mathrm{ob}$ ), and the interaction between two, as the main factors, and relative gene expression of each

155 specific cytokine as the dependent variable $(\alpha=0.05)$. Post hoc tests were carried out using

156 Fisher's LSD test and using a one-way ANOVA to determine significant interactions $(\alpha=0.05)$.

157 In some cases, logarithmic transformation was necessary to satisfy requirement of homogeneity

158 of variances. 
160 Results

\section{Body mass}

162 Body mass decreased after 24 hours of SF $\left(F_{1,30}=42.050, p<0.0001\right.$; Fig.1). Post-hoc tests

163 revealed that sleep treatment affected mass loss, despite the initial difference in body weight. SF

164 and OB SF mice lost significantly more body mass (on a percentage basis) than wild-type control

165 and OB control mice, respectively (Fisher's LSD; all $p<0.05$; Fig.1). Wild-type control mice

166 lost significantly more body mass (on a percentage basis) than OB controls (Fisher's LSD, $p<$

$1670.05)$.

\section{Peripheral Response}

169 Liver

170 No differences among groups in IL-1 $\beta$ gene expression were detected in the liver $(\log -$

171 transformed; interaction: $F_{2,27}=0.993 ; p=0.328$; sleep treatment: $F_{1,27}=0.809 ; p=0.377$; leptin

172 deficiency: $F_{1,27}=2.875 ; p=0.102$; Fig. 2). Liver TNF- $\alpha$ gene expression was elevated in OB

173 mice relative to wild-type controls (log-transformed; $F_{1,25}=6.750, p=0.020$; Fisher's LSD; all $p$

$174<0.05$; Fig. 2A). No other factors affected TNF- $\alpha$ gene expression (log-transformed; interaction:

$175 F_{2,25}=1.300 ; p=0.260$; sleep treatment: $F_{1,25}=2.080 ; p=0.160$; Fig. 2A). Leptin deficiency

176 also increased TGF- $\beta 1$ gene expression in liver (log-transformed; $F_{1,28}=12.350, p=0.002$;

177 Fisher's LSD; all $p<0.05$; Fig. 2) and no other factors were found to affect TGF- $\beta 1$ gene 
178 expression (log-transformed; interaction: $F_{2,28}=0.646 ; p=0.428$; sleep treatment: $F_{1,28}=1.257$;

$179 p=0.272)$.

180 Spleen

181 IL-1 $\beta$ gene expression decreased in the spleen due to leptin deficiency (log transformed;

$\left.182 F_{1,26}=6.390 ; p=0.02\right)$, although after conducting post-hoc tests, only ob SF mice exhibited

183 significantly lower levels than wild-type SF controls (Fisher's LSD, $p<0.05$ ). No other factors

184 affected IL-1 $\beta$ gene expression (interaction: $F_{2,26}=0.1 .233 ; p=0.277$; sleep treatment: $F_{1,26}$

$185=0.154 ; p=0.698$; Fig. 2B). There were no significant differences in TNF- $\alpha$ gene expression in

186 the spleen (log transformed; interaction: $F_{2,28}=0.292 ; p=0.594$; sleep treatment: $F_{1,28}=0.022 ; p$

$187=0.883$; leptin deficiency: $F_{1,28}=0.071 ; p=0.792$; Fig. 2B). Sleep fragmentation increased

188 TGF- $\beta 1$ gene expression in the spleen (log-transformed; $F_{1,25}=6.820, p=0.020$; Fisher's LSD;

189 all $p<0.05$; Fig. 2B). However, no other factors affected splenic TGF- $\beta 1$ gene expression (log-

190 transformed; interaction: $F_{2,25}=1.857, p=0.185$; leptin deficiency: $F_{1,25}=3.278, p=0.082$; Fig.

191 2B).

192

193 EWAT

194 OB mice decreased IL-1 $\beta$ gene expression in EWAT compared with wild-type mice (log-

195 transformed; $F_{1,26}=6.390 ; p=0.018$; Fisher's LSD; all $p<0.05$; Fig. $2 \mathrm{C}$ ). The interaction

196 between sleep treatment and genotype was also significant, with wild-type mice exposed to SF

197 exhibiting elevated IL-1 $\beta$ gene expression relative to other groups (log-transformed; $F_{2,26}=$

$1984.630 ; p=0.040$; Fisher's LSD; all $p<0.05$; Fig. 2C), except relative to the wild-type controls. 
199 TNF- $\alpha$ gene expression was altered in epididymal adipose tissue due to the interaction between 200 sleep treatment and genotype (log-transformed; $F_{2,28}=8.890 ; p=0.006$; Fisher's LSD; all $p<$ 201 0.05; Fig. 2C). Specifically, wild-type mice subjected to SF significantly increased TNF- $\alpha$ gene 202 expression in EWAT compared with wild-type controls $(P=0.002$; Fig.2), while leptin-deficient 203 mice failed to show such an elevation from SF compared with ob/ob controls $(P>0.05$; Fig.2C).

204 Ob/ob controls had significantly elevated TNF- $\alpha$ gene expression compared with wild-type 205 controls (Fisher's LSD, $p<0.05$; Fig. 2C;). No other factors affected TNF- $\alpha$ gene expression in 206 EWAT (log-transformed; sleep treatment: $F_{1,28}=3.963 ; p=0.056$; leptin deficiency: $F_{1,28}=$ $2070.095 ; p=0.760$; Fig. 2C). Similarly, none of the factors tested affected TGF- $\beta 1$ gene 208 expression in EWAT (interaction: $F_{2,28}=0.011, p=0.918$; sleep treatment: $F_{1,28}=0.002, p=$ 0.962; leptin deficiency: $F_{1,28}=0.037, p=0.849$; Fig. $2 \mathrm{C}$ ).

Heart

212 In cardiac muscle, OB mice exhibited decreased IL-1 $\beta$ (log-transformed, $F_{1,29}=50.720$;

$213 p<0.001$; Fisher's LSD; all $p<0.05$; Fig.2D) and TNF- $\alpha$ gene expression (log-transformed;

$214 F_{1,29}=28.960, p<0.001$; Fisher's LSD; all $p<0.05$; Fig. 2D) compared with wild-type controls.

215 However, no other factors affected IL-1 $\beta$ gene expression (log-transformed: interaction: $F_{2,29}=$ $2162.876, p=0.101$; sleep treatment: $F_{1,29}=0.003, p=0.956$; Fig. 2D). Sleep treatment also altered 217 TNF- $\alpha$ gene expression in heart (log-transformed; $F_{1,29}=16.106, p=0.0004$; Fig. 2D), but there 218 was no interaction effect between sleep treatment and leptin deficiency (log-transformed:

219 interaction: $F_{2,29}=1.660, p=0.208$; Fig. 2D). Leptin deficiency simultaneously resulted in 220 increased cardiac TGF- $\beta 1$ gene expression $\left(F_{1,29}=7.340 ; p<0.001\right.$; Fisher's LSD; all $p<0.05$; 
221 Fig. 3). No other factors affected TGF- $\beta 1$ gene expression in the heart (interaction: $F_{2,29}=1.014$,

$222 p=0.322$; sleep treatment: $F_{1,29}=3.275, p=0.081$; Fig. 2D).

223

224 Brain Response

225 Hippocampus

226 IL-1 $\beta$ gene expression was elevated in the hippocampus of ob/ob mice compared with wild-type

227 controls (log-transformed, $F_{1,28}=9.880, p=0.004$; Fisher's LSD; all $p<0.05$; Fig.4A).

228 Similarly, leptin deficiency increased TNF- $\alpha$ gene expression in the hippocampus relative to 229 wild-type SF and control mice (log-transformed, $F_{1,29}=24.540, p<0.0001$; Fisher's LSD; all $p$ $230<0.05$; Fig.4A). There were no other significant effects or interactions in IL-1 $\beta$ or TNF- $\alpha$ gene 231 expression (IL-1 $\beta$ : log-transformed, interaction: $F_{2,28}=0.165, p=0.688$; sleep: $F_{1,28}=2.218, p=$ 232 0.148; TNF- $\alpha$ : log-transformed; interaction: $F_{2,29}=4.123, p=0.052$; sleep treatment: $F_{1,29}=$ $2330.001, p=0.980$; Fig. 4A). For hippocampal TGF- $\beta 1$ gene expression, there were no significant 234 effects or interactions among groups (hippocampus: interaction: $F_{2,27}=1.116 ; p=0.300$; sleep 235 treatment: $F_{1,27}=0.074 ; p=0.787$; leptin deficiency: $F_{1,27}=0.127 ; p=0.724$; Fig. $4 \mathrm{~A}$ ).

Hypothalamus

237 Leptin-deficient mice exhibited elevated levels of hypothalamic IL-1 $\beta$ (log-transformed; $F_{1,26}=$ 238 11.640, $p=0.002$; Fisher's LSD; all $p<0.05$; Fig. 4B) and TNF- $\alpha$ (log-transformed, $239 F_{1,25}=29.270, p<0.0001$; Fisher's LSD; all $p<0.05$; Fig.4) compared with wild-type mice. No 240 other significant effects or interactions were apparent (hypothalamus IL-1 $\beta$ : log-transformed, 
241 interaction: $F_{2,26}=0.012, p=0.914$; sleep treatment: $F_{1,26}=0.002, p=0.962$; TNF- $\alpha$

242 hypothalamus: log-transformed; interaction: $F_{1.25}=0.655, p=0.426$; sleep treatment: $F_{2,25}=$

$2431.196, p=0.285)$. Lastly, hypothalamic TGF- $\beta 1$ gene expression did not vary significantly

244 among groups (log-transformed; interaction: $F_{2,25}=0.214 ; p=0.647$; sleep treatment: $F_{1,25}=$

$2452.294 ; p=0.142$; leptin deficiency: $\left.F_{1,25}=0.035 ; p=0.854\right)$.

246 Prefrontal cortex

247 Leptin-deficient mice exhibited elevated levels of IL-1 $\beta$ (log-transformed; leptin deficiency: $F_{1,27}$ $248=6.90 ; p=0.010$; Fisher's LSD; all $p<0.05$; Fig. 4C) and TNF- $\alpha$ (log-transformed; leptin 249 deficiency; $F_{1,27}=5.62 ; p<0.024$; Fisher's LSD; all $p<0.05$; Fig. 4 C) expression in prefrontal 250 cortex compared with wild-type controls. No other factors affected pro-inflammatory cytokine 251 gene expression in the hypothalamus, prefrontal cortex, or hippocampus (prefrontal cortex IL$2521 \beta$ : log- transformed; interaction: $F_{2,27}=0.264 ; p=0.612$; sleep treatment: $F_{1,27}=1.432 ; p=$ 253 0.242; TNF- $\alpha$ prefrontal cortex: log-transformed; interaction: $F_{2,27}=0.118 ; p=0.734$; sleep 254 treatment: $F_{1,27}=0.319 ; p=0.577$; leptin deficiency: $F_{1,27}=0.225 ; p=0.639$; hippocampus IL$2551 \beta$ : log-transformed, interaction: $F_{2,28}=0.165, p=0.688$; sleep: $F_{1,28}=2.218, p=0.148$; 256 hippocampus TNF- $\alpha$ : log-transformed; interaction: $F_{2,29}=4.123, p=0.052$; sleep treatment: $257 F_{1,29}=0.001, p=0.980$; all Fig. 4). There were no significant differences in TGF- $\beta 1$ gene 258 expression in any regions of the brain tested (hypothalamus, prefrontal cortex: interaction: $F_{2,28}$ $259=1.276 ; p=0.268 ;$ sleep treatment: $F_{1,28}=0.006 ; p=0.939 ;$ leptin deficiency: $F_{1,28}=0.066 ; p=$ $260 \quad 0.799 ;)$. 


\section{Serum corticosterone}

263 Serum corticosterone concentration varied significantly among groups due to sleep treatment

$264\left(F_{1,30}=41.100 ; p<0.0001 ;\right.$ Fisher's LSD; all $p<0.05$; Fig. 4). Specifically, acute sleep

265 fragmentation significantly increased baseline serum corticosterone in wild-type and ob/ob mice 266 compared with wild-type or ob/ob controls (all $p<0.03$ ). However, serum corticosterone 267 concentration did not differ significantly between $o b / o b$ and wild-type mice $\left(F_{1,30}=0.777 ; p=\right.$ 2680.385 ; Fig. 4$)$ or as a result of the interaction between sleep treatment and genotype $\left(F_{2,30}=\right.$ $2690.031 ; p=0.861$; Fig. 4).

270

\section{Discussion}

The findings of this study indicate that leptin-deficient mice produce different cytokine gene responses in the periphery versus the brain and that sleep fragmentation had little or no effect upon these differences. Therefore, the hypothesis that sleep fragmentation exacerbates peripheral and brain inflammation in leptin-deficient mice compared with wild-type controls is not supported. More specifically, leptin deficiency increased pro-inflammatory (IL-1 $\beta$, TNF- $\alpha$ ) cytokine gene expression in all areas of brain measured (hippocampus, hypothalamus, prefrontal cortex; Table 1). These results are consistent with a number of studies that have described hypothalamic inflammation in obese mice (either genetically or diet-induced) as well as presence

280 of neuroinflammation in hippocampus and cortex (Aguilar-Valles et al. 2014; Guillemot-Legris

281 \& Muccioli 2017; Lumeng \& Saltiel 2011). In the periphery, results were more complex (Table 282 1). In liver, TNF- $\alpha$ was elevated in ob mice compared with wild-type mice, but in other tissues, 283 ob mice exhibited decreased expression of IL-1 $\beta$ in spleen and IL-1 $\beta$ and TNF- $\alpha$ in heart 
284 compared with wild-type mice (Table 1). Furthermore, there was a general upregulation of TGF-

$285 \beta 1$ in liver, spleen, and heart in ob mice compared with wild-type controls. The propensity

286 toward an anti-inflammatory response in important metabolic tissue could be protective, as obese

287 individuals would be at the greatest risk for the development of metabolic abnormalities (Youn et

288 al. 2014). The increase in TGF- $\beta 1$ and decrease in pro-inflammatory cytokine (IL-1 $\beta$, TNF- $\alpha$ )

289 expression in heart of ob mice was unexpected and potentially indicative of an anti-inflammatory

290 environment that may also be protective, although additional study is required. This result

291 contrasts with previous research that shows that leptin-deficiency increases inflammation and

292 hypertrophy in the mouse heart (Unsold et al. 2015).

There were few tissues affected by acute SF in this study, although there were certainly

294 some notable non-significant trends that may require further examination (e.g., TNF $-\alpha$ in liver).

295 There was a significant increase in IL-1 $\beta$ expression in epipidymal white adipose tissue among

296 wild-type mice exposed to $24 \mathrm{~h}$ of sleep fragmentation (relative to non-sleep fragmented

297 controls) which is consistent with a previous study in our lab (Dumaine \& Ashley 2015). Among

298 wild-type mice, acute sleep fragmentation also increased TNF- $\alpha$ expression in EWAT as well as

299 increased expression of TGF- $\beta 1$ in spleen. Interestingly, ob mice were unresponsive to the

300 effects of acute sleep fragmentation compared with wild-type mice. Although further study is

301 needed, perhaps ob mice have pre-existing "metainflammation" (Lumeng \& Saltiel 2011) that

302 precludes further responses from sleep fragmentation (He et al. 2015; Pak et al. 2014). It is well

303 known that chronic exposure to sleep fragmentation and the hypoxic intervals associated with

304 OSA results in cell damage (Pak et al. 2014). More specifically, damage from oxidative stress

305 and inflammation in pancreas, liver, heart, and adipose tissue are hypothesized to result in

306 reduced insulin sensitivity, reduced glucose clearance, and disruption of elastic fibers in cardiac 
307 vessel endothelium that is associated with chronic SF (Carreras et al. 2014; Jia et al. 2014; Youn

308 et al. 2014; Zhang et al. 2014). Previous literature indicates pro-inflammatory and anti-

309 inflammatory cytokines have increased expression in the tissue of obese individuals compared

310 with lean individuals (Fjeldborg et al. 2014).

311 Additional studies have shown elevated IL-1 $\beta$ expression in the mouse brain following

312 sleep deprivation, while the expression of TNF- $\alpha$ has varied depending upon the study

313 (Chennaoui et al. 2011; Weil et al. 2009; Zielinski et al. 2014). In contrast to previous literature,

314 leptin deficiency was reported as the only factor that affected pro-inflammatory cytokine gene

315 expression in the brain. Sleep treatment did not significantly affect brain IL-1 $\beta$ or TNF- $\alpha$ gene

316 expression in this experiment. This is surprising considering that previous research has indicated

317 that the same frequency of SF induces neuroinflammation in the hypothalamus (Dumaine and 318 Ashley, 2015).

319 Chronic SF increases orexigenic behavior, while caloric expenditure remains unchanged,

320 ultimately leading to weight gain from excess food intake (Carreras et al. 2014; Wang et al.

321 2014). Weight gain is typically mediated by alterations in the expression of leptin and ghrelin,

322 which are satiety and orexigenic hormones, respectively, that act antagonistically on the

323 hypothalamus to maintain energy balance (Garcia-Garcia et al. 2014). Although ob/ob mice are

324 leptin gene KOs, sleep fragmented leptin-deficient mice and wild-type mice lost significant

325 body mass when compared with control mice. Consequently, the alterations in orexigenic

326 behavior following sleep curtailment are likely multifaceted and cannot be explained solely by

327 alterations in ghrelin and leptin, at least in the short term (Pak et al. 2014). Furthermore, body

328 mass fluctuations following acute SF could also be affected by a physiological stress response

329 or decreased food intake, coupled with increased locomotion during the prolonged period of 
330 wakefulness. While weight gain is typically observed in chronic murine SF experiments, this

331 weight gain is time-dependent. The progression towards metabolic syndrome, characterized by

332 reduced glucose clearance and insulin sensitivity, does not alter body mass until multiple days

333 of exposure to sleep fragmentation (Carreras et al. 2014; Dumaine \& Ashley 2015).

334 Consequently, the mass loss observed in leptin-deficient and wild-type mice following acute

335 sleep fragmentation is likely due to a combination of increased activity and reduced food intake.

336 We speculate that the slight mass loss observed in non-sleep-fragmented mice is probably a

337 result of subjects being exposed to a novel environment, which may have produced some

338 anxiety/fear that interrupted normal food intake.

The observed alterations in cytokine gene expression in this experiment were detected at

340 the mRNA level. While previous experimentation has shown that mRNA and protein expression

341 levels of TNF- $\alpha$ are correlated following experimental sleep loss and vaccine stimulation,

342 experiments involving IL-1 $\beta$ have produced conflicting results and TGF- $\beta 1$ has not been studied

343 within this context (Irwin et al. 2006; Shebl et al. 2010). However, more recent literature

344 suggests that fold changes in protein expression are largely regulated by alterations in mRNA

345 abundance; moreover, other processes, such as protein degradation, may also affect the proteome

346 (Jovanovic et al. 2015). Consequently, it is equivocal whether protein levels correlate directly

347 with mRNA expression, but nonetheless, increased mRNA expression still provides insight into

348 the rapid temporal dynamics of cytokine activation at the transcriptional level.

349 Sleep treatment altered serum corticosterone concentration independently of initial body

350 mass. Both the wild-type and leptin-deficient SF groups exhibited increased serum

351 glucocorticoid concentrations compared with non-SF controls, but there was no difference

352 detected between the SF groups. SF was the only factor affecting alterations in stress hormone 
353 levels, as reported in previous experiments (Ashley et al. 2013; Bonnavion et al. 2015; Nieto et

354 al. 2000). Although ob/ob mice exhibit hypercorticosteronemia, serum corticosterone

355 concentration was not different between obese leptin-deficient and wild-type mice. Furthermore,

356 the increase in serum corticosterone concentration and mass loss as a result of SF is consistent

357 with a previous study (Dumaine \& Ashley 2015). Alternatively, increases in serum

358 corticosterone concentration could have been attributed to two possibilities: a.) a shift in natural

359 biological rhythms from forced arousals during the light phase of the LD cycle and/or b.) an

360 increase in activity levels in the SF groups as a result of tactile stimulation from the swipe bar.

361 The combination of body mass loss and elevated serum corticosterone concentrations suggests

362 that SF mice were experiencing a physiological stress response, including activation of the HPA

363 axis, as a result of sleep interruptions occurring so frequently. A recent study from our laboratory

364 has also demonstrated that exposure to novel environments (such as new cages) can also affect

365 inflammatory and adrenocortical responses to sleep loss (Ashley et al. 2016). Therefore, it is

366 unresolved whether HPA activation occurred because of the method of sleep fragmentation used

367 or the direct effect of disrupted sleep per se.

369 Conclusion

This experiment provides evidence for differential cytokine gene expression between

371 obese leptin-deficient and wild type mice exposed to acute sleep fragmentation. Since the genetic

$372 \mathrm{KO}$ used in this experiment may affect pro-inflammatory cytokine gene expression, replication

373 within the context of a diet-induced model of obesity would be helpful. Presently, the results

374 suggest that a pro-inflammatory environment was induced in the brain of leptin-deficient mice,

375 while a largely anti-inflammatory effect was produced in the periphery, despite heightened serum 
376 corticosterone concentrations. Because the response to SF is different between wild-type and

377 leptin-deficient animals, these results may imply different treatment options in terms of

378 therapeutic methods for individuals with OSA. For example, to treat inflammation in obese

379 patients due to leptin resistance, preventative measures, such as reducing body weight through

380 diet and exercise, would likely be effective, rather than solely treating inflammation created as a

381 result of SF. Consistent with our previous work, a single 24 hour SF period was sufficient to

382 induce a pro-inflammatory environment in adipose tissue. Since acute sleep loss can lead to

383 chronic effects, manipulating sleep over a longer timeframe will provide needed insights into

384 inflammation-induced pathology associated with chronic conditions, such as OSA.

386 Acknowledgements

Thanks to Naomi Rowland for assistance with RT-PCR and other protocols and the

WKU Biotechnology Center for access to resources. This work was funded by an Institutional

389 Development Award (IDeA) grant from the NIGMS under grant number 5P20GM103436 (to

390 NTA), NIH R15GM117534 (to NTA) and a Graduate Studies Research Grant from Western

391 Kentucky University (to JED).

392

393 Literature Cited

394 Aguilar-Valles A, Inoue W, Rummel C, and Luheshi GN. 2015. Obesity, adipokines and 
396 Al Maskari MY, and Alnaqdy AA. 2006. Correlation between Serum Leptin Levels, Body Mass 397 Index and Obesity in Omanis. Sultan Qaboos Univ Med J 6:27-31.

398 Ashley NT, Sams DW, Brown AC, and Dumaine JE. 2016. Novel environment influences the

399 effect of paradoxical sleep deprivation upon brain and peripheral cytokine gene

400 expression. Neurosci Lett 615:55-59. 10.1016/j.neulet.2016.01.013

401

402

403

404

405

406

407

408

409

410

411

412

413

414

415

416

417

418

Ashley NT, Walton JC, Haim A, Zhang N, Prince LA, Fruchey AM, Lieberman RA, Weil ZM, Magalang UJ, and Nelson RJ. 2013. Sleep deprivation attenuates endotoxin-induced cytokine gene expression independent of day length and circulating cortisol in male Siberian hamsters (Phodopus sungorus). J Exp Biol 216:2581-2586. 10.1242/jeb.083832

Besedovsky L, Lange T, and Born J. 2012. Sleep and immune function. Pflugers Arch 463:121137. $10.1007 / \mathrm{s} 00424-011-1044-0$

Bonnavion P, Jackson AC, Carter ME, and de Lecea L. 2015. Antagonistic interplay between hypocretin and leptin in the lateral hypothalamus regulates stress responses. Nat Commun 6:6266. $10.1038 /$ ncomms 7266

Carreras A, Zhang SX, Peris E, Qiao Z, Gileles-Hillel A, Li RC, Wang Y, and Gozal D. 2014. Chronic sleep fragmentation induces endothelial dysfunction and structural vascular changes in mice. Sleep 37:1817-1824. 10.5665/sleep.4178

Chennaoui M, Sauvet F, Drogou C, Van Beers P, Langrume C, Guillard M, Gourby B, Bourrilhon C, Florence G, and Gomez-Merino D. 2011. Effect of one night of sleep loss on changes in tumor necrosis factor alpha (TNF-alpha) levels in healthy men. Cytokine 56:318-324. 10.1016/j.cyto.2011.06.002

Dinarello CA. 2010. Anti-inflammatory Agents: Present and Future. Cell 140:935-950. 10.1016/j.cell.2010.02.043 
419 Dube MG, Torto R, and Kalra SP. 2008. Increased leptin expression selectively in the

420 hypothalamus suppresses inflammatory markers CRP and IL-6 in leptin-deficient diabetic obese mice. Peptides 29:593-598. 10.1016/j.peptides.2008.01.001

422

423

424 425

426

427

428

429

430

431

432

433

434

435

436

437

438

439

440

Dumaine JE, and Ashley NT. 2015. Acute sleep fragmentation induces tissue-specific changes in cytokine gene expression and increases serum corticosterone concentration. Am J Physiol Regul Integr Comp Physiol 308:R1062-1069. 10.1152/ajpregu.00049.2015

Fjeldborg K, Pedersen SB, Moller HJ, Christiansen T, Bennetzen M, and Richelsen B. 2014. Human adipose tissue macrophages are enhanced but changed to an anti-inflammatory profile in obesity. J Immunol Res 2014:309548. 10.1155/2014/309548

Fruhbeck G, Catalan V, Rodriguez A, Ramirez B, Becerril S, Portincasa P, and Gomez-Ambrosi J. 2017. Normalization of adiponectin concentrations by leptin replacement in ob/ob mice is accompanied by reductions in systemic oxidative stress and inflammation. Sci Rep 7:2752. 10.1038/s41598-017-02848-0

Fu C, Jiang L, Zhu F, Liu Z, Li W, Jiang H, Ye H, Kushida CA, and Li S. 2015. Chronic intermittent hypoxia leads to insulin resistance and impaired glucose tolerance through dysregulation of adipokines in non-obese rats. Sleep Breath 19:1467-1473. $10.1007 / \mathrm{s} 11325-015-1144-8$

Garcia-Garcia F, Juarez-Aguilar E, Santiago-Garcia J, and Cardinali DP. 2014. Ghrelin and its interactions with growth hormone, leptin and orexins: implications for the sleep-wake cycle and metabolism. Sleep Med Rev 18:89-97. 10.1016/j.smrv.2013.04.003

Guillemot-Legris O, and Muccioli GG. 2017. Obesity-Induced Neuroinflammation: Beyond the Hypothalamus. Trends Neurosci 40:237-253. 10.1016/j.tins.2017.02.005 
441 He J, Kastin AJ, Wang Y, and Pan W. 2015. Sleep fragmentation has differential effects on $442 \quad$ obese and lean mice. J Mol Neurosci 55:644-652. 10.1007/s12031-014-0403-7

443 Irwin MR, Wang M, Campomayor CO, Collado-Hidalgo A, and Cole S. 2006. Sleep deprivation 444 and activation of morning levels of cellular and genomic markers of inflammation. Arch $445 \quad$ Intern Med 166:1756-1762.

446 Jia L, Vianna CR, Fukuda M, Berglund ED, Liu C, Tao C, Sun K, Liu T, Harper MJ, Lee CE, 447 Lee S, Scherer PE, and Elmquist JK. 2014. Hepatocyte Toll-like receptor 4 regulates obesity-induced inflammation and insulin resistance. Nat Commun 5:3878.

Jovanovic M, Rooney MS, Mertins P, Przybylski D, Chevrier N, Satija R, Rodriguez EH, Fields AP, Schwartz S, Raychowdhury R, Mumbach MR, Eisenhaure T, Rabani M, Gennert D, Lu D, Delorey T, Weissman JS, Carr SA, Hacohen N, and Regev A. 2015. Immunogenetics. Dynamic profiling of the protein life cycle in response to pathogens. Science 347:1259038. 10.1126/science.1259038 Clin Invest 121:2111-2117. 10.1172/jci57132

Lv D, Tan L, Wu Y, Cao C, and Deng Z. 2015. Leptin and leptin receptor gene polymorphisms 461 in obstructive sleep apnea: a HuGE review and meta-analysis. Sleep Breath 19:10731078. 10.1007/s11325-015-1120-3 
463 Mirsoian A, Bouchlaka MN, Sckisel GD, Chen M, Pai CC, Maverakis E, Spencer RG, Fishbein 464 KW, Siddiqui S, Monjazeb AM, Martin B, Maudsley S, Hesdorffer C, Ferrucci L, Longo 465 DL, Blazar BR, Wiltrout RH, Taub DD, and Murphy WJ. 2014. Adiposity induces lethal 466 cytokine storm after systemic administration of stimulatory immunotherapy regimens in 467 aged mice. J Exp Med 211:2373-2383. 10.1084/jem.20140116

468

469

470

471

472

473

474

475

476

477

478

479

480

481

482

483

484

485

Nieto FJ, Young TB, LInd BK, Shahar E, Samet MM, Redline S, D'Agostino RB, Newman AB, Lebowitz MD, and Pickering TG. 2000. Association of sleep-disordered breathing, sleep apnea, and hypertension in a large community-based study. JAMA 283:1829-1836.

O'Donnell CP, Tankersley CG, Polotsky VP, Schwartz AR, and Smith PL. 2000. Leptin, obesity, and respiratory function. Respir Physiol 119:163-170.

Ozturk L, Unal M, Tamer L, and Celikoglu F. 2003. The association of the severity of obstructive sleep apnea with plasma leptin levels. Arch Otolaryngol Head Neck Surg 129:538-540. 10.1001/archotol.129.5.538

Pak VM, Grandner MA, and Pack AI. 2014. Circulating adhesion molecules in obstructive sleep apnea and cardiovascular disease. Sleep Med Rev 18:25-34. 10.1016/j.smrv.2013.01.002

Pan W, and Kastin AJ. 2014. Leptin: a biomarker for sleep disorders? Sleep Med Rev 18:283290. 10.1016/j.smrv.2013.07.003

Peppard PE, Young T, Barnet JH, Palta M, Hagen EW, and Hla KM. 2013. Increased prevalence of sleep-disordered breathing in adults. Am J Epidemiol 177:1006-1014. 10.1093/aje/kws342

Ramesh V, Kaushal N, and Gozal D. 2009. Sleep Fragmentation Differentially Modifies EEG Delta Power During Slow Wave Sleep in Socially Isolated and Paired Mice. Sleep Sci 2:6475. 
486 Sainz N, Rodriguez A, Catalan V, Becerril S, Ramirez B, Gomez-Ambrosi J, and Fruhbeck G.

487 2010. Leptin administration downregulates the increased expression levels of genes

488 related to oxidative stress and inflammation in the skeletal muscle of ob/ob mice.

489 Mediators Inflamm 2010:784343. 10.1155/2010/784343

490 Sanjabi S, Zenewicz LA, Kamanaka M, and Flavell RA. 2009. Anti-inflammatory and pro-

491 inflammatory roles of TGF-beta, IL-10, and IL-22 in immunity and autoimmunity. Curr

492 Opin Pharmacol 9:447-453. 10.1016/j.coph.2009.04.008

493 Shebl FM, Pinto LA, Garcia-Pineres A, Lempicki R, Williams M, Harro C, and Hildesheim A.

494 2010. Comparison of mRNA and protein measures of cytokines following vaccination

495

496

with human papillomavirus-16 L1 virus-like particles. Cancer Epidemiol Biomarkers

497 Unsold B, Bremen E, Didie M, Hasenfuss G, and Schafer K. 2015. Differential PI3K signal

498

499

transduction in obesity-associated cardiac hypertrophy and response to ischemia. Obesity (Silver Spring) 23:90-99. 10.1002/oby.20888

500 Wang Y, Carreras A, Lee S, Hakim F, Zhang SX, Nair D, Ye H, and Gozal D. 2014. Chronic

501 sleep fragmentation promotes obesity in young adult mice. Obesity (Silver Spring)

502 22:758-762. 10.1002/oby.20616

503 Weil ZM, Norman GJ, Karelina K, Morris JS, Barker JM, Su AJ, Walton JC, Bohinc S, Nelson 504 RJ, and DeVries AC. 2009. Sleep deprivation attenuates inflammatory responses and $505 \quad$ ischemic cell death. Exp Neurol 218:129-136.

506 Youn JY, Siu KL, Lob HE, Itani H, Harrison DG, and Cai H. 2014. Role of vascular oxidative 507 stress in obesity and metabolic syndrome. Diabetes 63:2344-2355. 10.2337/db13-0719 
508 Zhang SX, Khalyfa A, Wang Y, Carreras A, Hakim F, Neel BA, Brady MJ, Qiao Z, Hirotsu C, 509 and Gozal D. 2014. Sleep fragmentation promotes NADPH oxidase 2-mediated adipose

510 tissue inflammation leading to insulin resistance in mice. Int J Obes (Lond) 38:619-624.

$511 \quad 10.1038 /$ ijo.2013.139

512 Zielinski MR, Kim Y, Karpova SA, McCarley RW, Strecker RE, and Gerashchenko D. 2014.

513 Chronic sleep restriction elevates brain interleukin-1 beta and tumor necrosis factor-alpha

514 and attenuates brain-derived neurotrophic factor expression. Neurosci Lett 580:27-31.

$515 \quad$ 10.1016/j.neulet.2014.07.043 


\section{Table $\mathbf{1}$ (on next page)}

Summary of the effects of leptin deficiency and sleep fragmentation on cytokine gene expression in peripheral and brain tissues 


\begin{tabular}{|l|l|l|}
\hline Tissue & Effect & Factor \\
\hline Liver & Increase: TNF- $\alpha$ and TGF- $\beta 1$ & Leptin deficiency \\
\hline Spleen & Increase: TGF- $\beta 1$ & Sleep Fragmentation \\
\hline & Decrease: IL-1 $\beta$ (SF ob mouse) & Interaction \\
\hline EWAT & $\begin{array}{l}\text { Increase: IL-1 } \beta ; \text { TNF- } \alpha \text { (SF, } \\
\text { wild-type) }\end{array}$ & Interaction \\
\hline Heart & Decrease: IL-1 $\beta$ and TNF- $\alpha$ & Leptin deficiency \\
\hline Hippocampus & Increase: TGF- $\beta 1$ & Leptin deficiency \\
\hline Hypothalamus & Increase: IL-1 $\beta$ and TNF- $\alpha$ & Leptin deficiency \\
\hline Prefrontal Cortex & Increase: IL- $1 \beta$ and TNF- $\alpha$ & Leptin deficiency \\
\hline
\end{tabular}

2 
Figure 1

Body mass loss in leptin-deficient and wild-type (lean) mice exposed to SF or control conditions for 24 hours.

Data are shown as \% change in body mass \pm SE for each group. Shared letters indicate no significant difference between groups. The numbers at the base of the column indicate the sample size of each group.

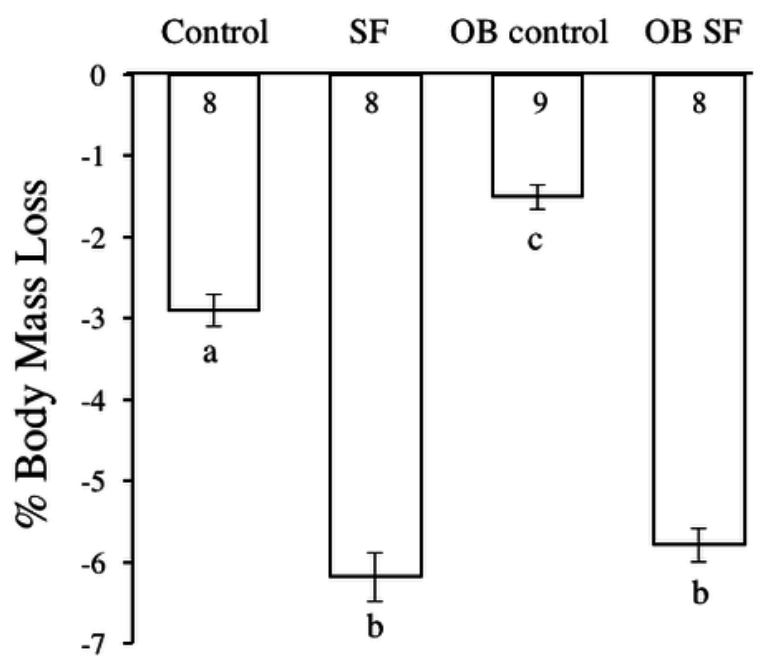


Figure 2

Effects of fragmented sleep, leptin deficiency, and their interaction upon cytokine gene expression in peripheral tissues

(A) liver, (B) spleen, (C) epididymal adipose tissue, (D) heart. Data are shown as mean $\pm \mathrm{SE}$ for each group. Sample size ranged from $N=6-9$, as several samples were undetectable by RT-PCR in some tissue samples. $*$ denotes $p<0.05$ relative to non-SF vehicle control. $\dagger$ denotes $p<0.05$ relative to group(s) indicated by horizontal $\operatorname{bar}(\mathrm{s}) . \ddagger$ denotes $p<0.05$ relative to all other groups.

A

\section{Liver}

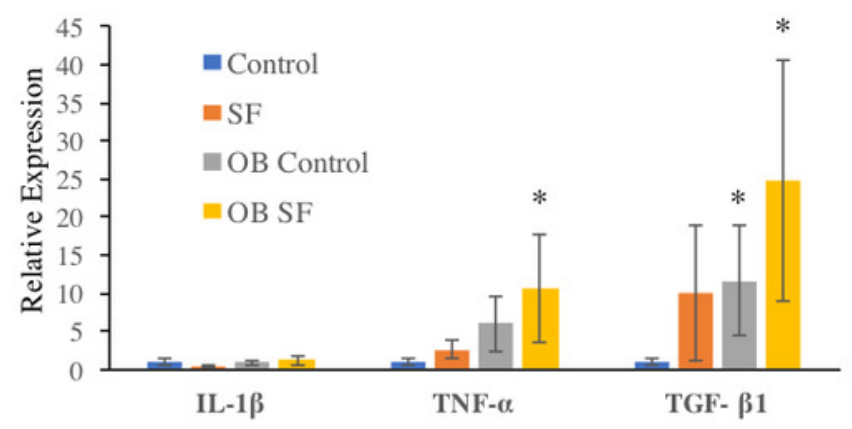

C

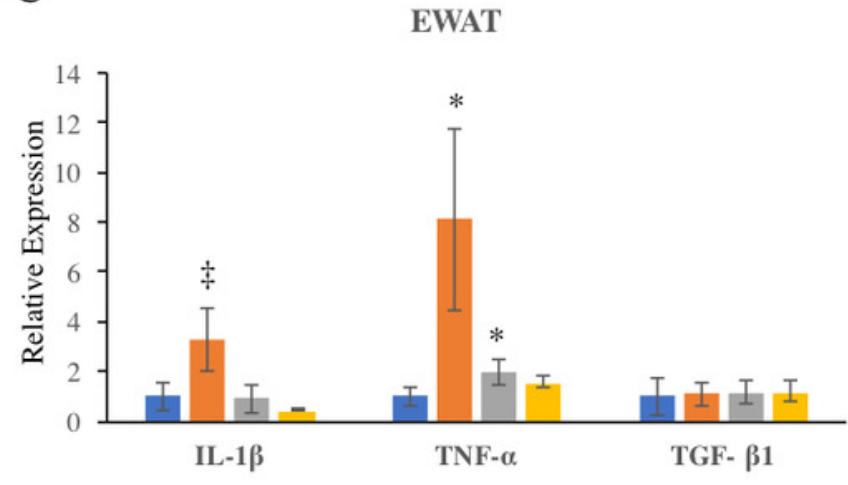

B

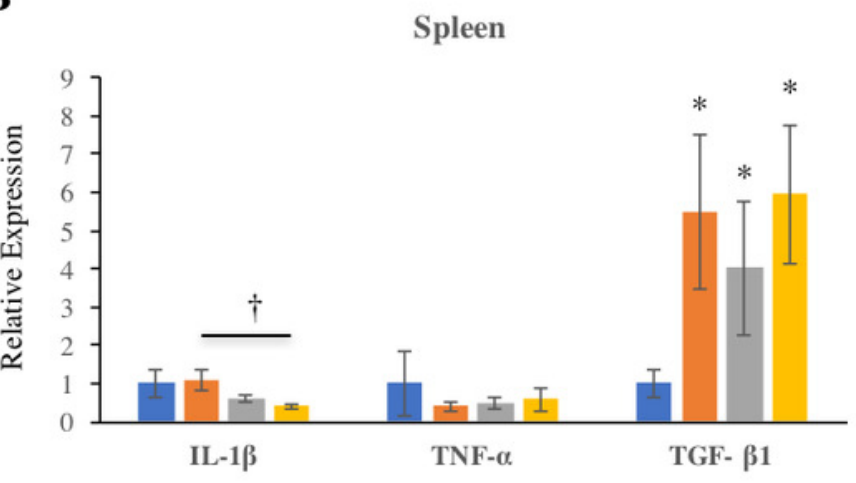

D

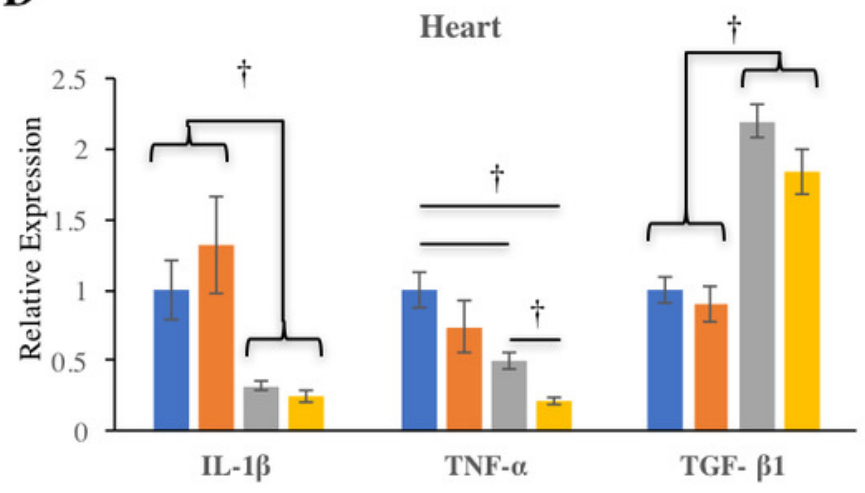


Figure 3

Effects of fragmented sleep, leptin deficiency, and their interaction upon cytokine gene expression in the brain

(A) hippocampus, (B) hypothalamus, and (C) prefrontal cortex. Data are shown as mean $\pm \mathrm{SE}$ for each group. Sample size ranged from $N=6-9$, as several samples were undetectable by RT-PCR in some tissue samples. $*$ denotes $p<0.05$ relative to non-SF vehicle control. $\dagger$ denotes $p<0.05$ relative to group(s) indicated by horizontal bar(s).

A

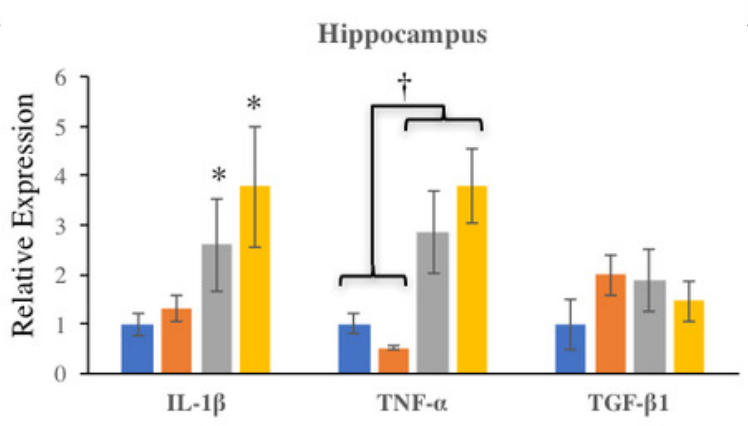

C

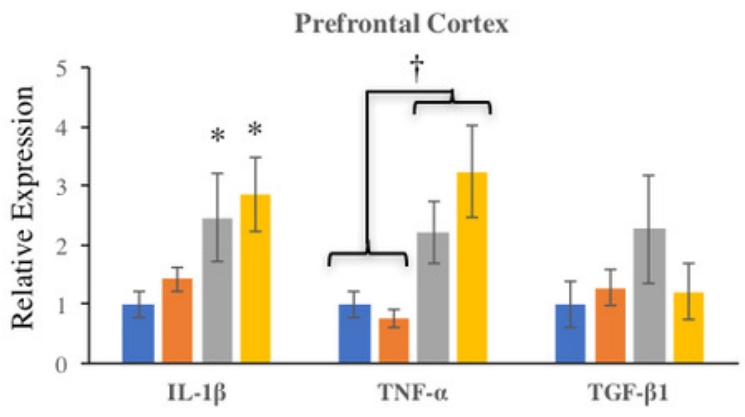

B

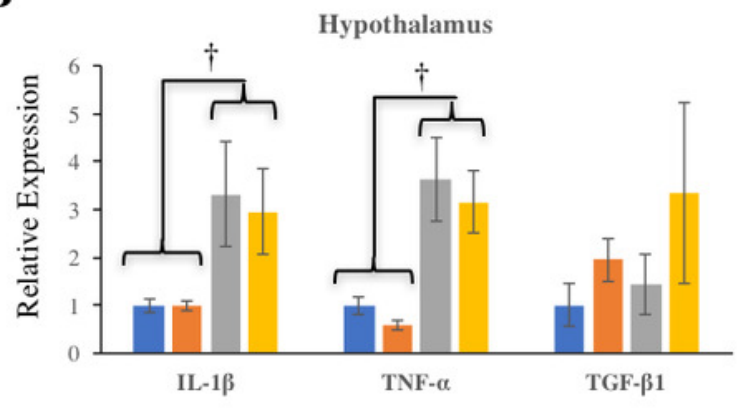


Figure 4

Serum corticosterone concentrations after $24 \mathrm{~h}$ of sleep fragmentation or control conditions in wild-type (lean) and leptin-deficient mice

Data are shown as mean $(\mathrm{ng} / \mathrm{ml}) \pm \mathrm{SE}$ for each group. Shared letters indicate there is no significant difference between groups. Numbers at the base of the column indicate sample size.

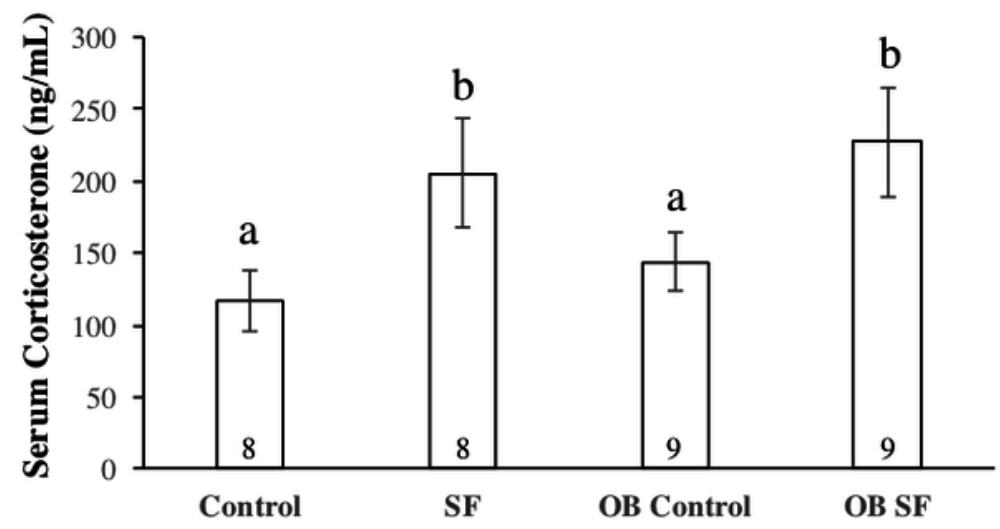

